\title{
a escrita compartilhada. monteiro lobato, rãzinha e a reforma da natureza ${ }^{1}$
}

\author{
patricia tavares raffaini ${ }^{2}$ \\ universidade de são paulo - brasil
}

resumo

Monteiro Lobato ainda hoje é considerado um dos autores de literatura infanto-juvenil mais importante no Brasil. Durante as décadas de trinta e quarenta do século XX, quando ele era sem dúvida o autor mais lido e admirado pelas crianças, ele se correspondeu com inúmeros leitores de todo o país. Por meio das cartas percebemos vários aspectos de como a leitura era feita, o cotidiano das crianças e dos jovens, e suas opiniões sobre política. Porém, o que essa documentação nos mostra de mais interessante é a recepção da obra de Lobato pelo seu público leitor. Mais do que isso a epistolografia trocada com crianças e jovens nos revela como o autor construía sua obra em consonância com as reflexões que seus jovens leitores faziam, assim como frequentemente modificava suas narrativas em parte atendendo aos pedidos das crianças. Nesse artigo pretendemos analisar um conjunto de cartas específicas que o escritor recebeu de uma menina: Maria de Lurdes. A leitora se correspondeu com Lobato no início da década de 40 e em suas cartas encontramos inúmeras sugestões que foram incorporadas ao texto da obra Reforma da Natureza. As sugestões dadas foram tão importantes que o autor a transforma em uma personagem, e durante toda a narrativa ela e Emília se divertem modificando animais, plantas e insetos do Sítio do Picapau Amarelo.

palavras-chaves: história da leitura; literatura infanto-juvenil; Monteiro Lobato

\section{the shared writing: monteiro lobato, the little frog and the renovation of nature}

\section{abstract}

Monteiro Lobato is still nowadays considered one of the most important authors of children's literature in our country. During the thirties and fourties of the twentieth century, when he was arguably the most read and admired author for children, he corresponded with countless readers from all over Brazil. Through the letters we perceive many aspects of how reading was done, the daily life of children and young people, their opinions about politics, but what this documentation reveals of most interesting to us is the reception of Lobato's work by his readership. More than that, the epistolographie with children and young people reveals how he was attentive to the reception of his work among them and also how he modified his narratives, having as collaborators his own readers. In this article we intend to analyze a specific set of letters that the writer received from a girl: Maria de Lourdes. The reader not only corresponded with Lobato but also gave so many suggestions for his work that she

\footnotetext{
${ }^{1}$ Esse artigo é um dos resultados da pesquisa de doutorado realizada pela autora e financiada pelo $\mathrm{CNPq}$, uma versão preliminar desse trabalho foi apresentada no $1^{\circ}$ Congresso de Estudos da Infância, organizado pelo Departamento de Estudos da Infância da Faculdade de Educação da Universidade do Estado do Rio de Janeiro, EDU/UERJ.

${ }^{2}$ E-mail: raffaini@usp.br
} 
became one of the characters in the work Reforma da Natureza, where she helped throughout the narrative the character Emília as they modify animals, plants and insects of the Sitio do Picapau Amarelo.

keywords: reading history; childhood literature; Monteiro Lobato

\section{la escritura compartida. monteiro lobato, ranita y la reforma de la naturaleza}

resumen

Monteiro Lobato es considerado uno de los escritores de literatura infanto-juvenil más importantes de Brasil. En las décadas del treinta y del cuarenta del siglo XX, cuando era ciertamente el escritor más leído y admirado por los niños, el autor intercambiaba correspondencia con incontables lectores de todo el país. Por medio de las cartas percibimos varios aspectos de cómo se realizaba la lectura, la vida cotidiana de los niños y de los jóvenes y sus opiniones sobre política. Sin embargo, lo más interesante que nos muestra esa documentación es la recepción de la obra de Lobato por su público lector. El estudio de estas epístolas nos revela cómo el escritor construía su obra en consonancia con las reflexiones que sus jóvenes lectores hacían, cómo frecuentemente el cambiaba sus narrativas en parte para atender solicitudes de los niños. En este artículo pretendemos analizar un conjunto de correspondencias específicas que el escritor recibió con una niña: Maria de Lurdes. La lectora se correspondió con Lobato a comienzos de la década del 40 y en sus cartas encontramos sugerencias que fueran añadidas al texto de la obra Reforma da Natureza. Las sugerencias dadas por la niña fueron tan importantes que el escritor la transforma en un personaje y, a lo largo de la narrativa, ella y Emília se divierten modificando animales, plantas e insectos del Sítio do Picapau Amarelo.

palavras clave: historia de la lectura; literatura infanto-juvenil; Monteiro Lobato. 
a escrita compartilhada. monteiro lobato, rãzinha e a reforma da natureza

Em maio de 1946, Monteiro Lobato escreve à amiga Marina Andrada Procópio de Carvalho enviando um caderno de anotações com ideias e rascunhos feitos provavelmente a partir de 1917, além de um conjunto de mais de trezentas cartas enviadas a ele por crianças e jovens leitores ${ }^{3}$. O autor se mudava para Buenos Aires e pretendia lá ficar por um bom tempo; fazia, então, uma organização do seu arquivo pessoal e da sua biblioteca, encarregando tanto Marina Andrada como Edgard Cavalheiro de preservarem parte de sua documentação. As cartas enviadas pelos leitores, principalmente as escritas pelas crianças, eram seu tesouro particular, pois através delas Lobato percebia que sua produção surtia efeito e estabelecia com as crianças um diálogo muito importante.

Essa preciosa correspondência que ele deixava sob a responsabilidade de Marina compreendia os anos de 1932 à 1946, período correspondente aos anos que Lobato morou em São Paulo, entre sua estada como adido cultural em Nova Iorque e o ano de sua mudança para Buenos Aires. As cartas haviam sido enviadas por crianças de todo o Brasil e do estrangeiro, e estabeleciam com o autor um diálogo que versava sobre muitos assuntos. Em sua maioria, as correspondências comentavam as obras lidas do autor, aspectos da vida cotidiana das crianças e jovens, muitas também faziam os pedidos mais variados, como, por exemplo, encontros pessoais, sugestões de traduções de outros livros, o envio de um pouco de pó do pirlimpimpim, expressavam ainda opiniões políticas e muitos outros assuntos. Mas, sem dúvida, o que mais aparece em toda a correspondência são comentários sobre a obra infantojuvenil de Lobato. As crianças e jovens comentavam as obras lidas e sugeriam mudanças, personagens e novos temas para a escrita. $\mathrm{O}$ interessante é que o autor não

\footnotetext{
${ }^{3} \mathrm{O}$ caderno manuscrito, chamado nessa carta de "caderno-documento", assim como todas as cartas citadas nesse artigo, pertencem ao dossiê Monteiro Lobato, Fundo Raul de Andrada e Silva, conservado no Arquivo do Instituto de Estudos Brasileiros, IEB/USP.
} 
só lia as cartas com atenção como aproveitava essas sugestões e, muitas vezes, fazia alterações em seus livros guiado pela recepção das obras pelas crianças.

Lobato era de fato um escritor atento ao que as crianças pensavam e talvez o enorme sucesso de sua obra esteja relacionado a essa escuta atenta e cuidadosa da infância. No caderno que foi doado por ele a Marina, há, além do início de Narizinho Arrebitado, muitas frases proferidas por seus filhos durante os primeiros anos da infância. Desta forma, esse artigo pretende mostrar como Lobato aproveitava a correspondência que trocava com as crianças para verificar se suas narrativas agradavam seus leitores e, a partir dessa recepção, como o autor inúmeras vezes fez alterações em suas obras com o objetivo de aproximá-las do que as crianças mais gostavam. Essa postura é comentada por Lobato na Conferência "A criança é a humanidade de amanhä":

[...] Não possuo a mínima autoridade pedagógica de qualquer gênero, e tudo quanto sei de educação se resume em arruinar a exceção em favor da regra. Apesar disso escrevi uns livros que as crianças gostam de ler. E porque gostam as crianças de ler esses livros? Talvez pelo fato de serem escritos por elas mesmas através de mim. Como as coitadinhas não sabem escrever, admito que me pedem que o faça. Mas não que o faça como quero e sim como querem elas. Há de ser assim, assim, assim - e humildemente anulo-me para dar a minha clientelazinha um produto que não lhes desagrade 4 .

Lobato coloca a criança como um agente importante de sua criação literária.

Mais a frente, ainda neste mesmo texto, ele relata a experiência de se contar uma história para uma criança, e como ela ao escutá-la vai modificando-a, tornando-se quase sua coautora:

Faça-se a experiência. Conte-se uma história qualquer a uma criança. Ela a vai recebendo com reações muito dignas de estudo. Vai corrigindo-a no sentido de pô-la de acordo com as exigências da sua imaginação. E se o contador possui a necessária inteligência para atender a essas reações, a história modifica-se até cair em ponto de bala.

Imagino que ao ser contada pela primeira vez a história da menina de capinha vermelha, a primeira criança que a ouviu determinou de início, dois pontos: a capinha e a cor da capinha. 'Era uma vez uma menina que usava um vestido azul', teria começado uma vovó lá no fundo da Germânia. A loura Gretchen, de quatro anos, que friorentamente a ouvia - vendo através

${ }^{4}$ LOBATO, 1968, p. 250. 
da vidraça a neve cair, interrompeu-a ai para a primeira colaboração. 'Vestidinho, não, vovó - capinha'. Muito mais interessante com aquele frio uma capinha de lã, lã quente. 'Azul também não, vovó - vermelha'. O azul é frio, o vermelho é quente. E a história da menina do vestidinho azul passou a ser a história da menina da capinha vermelha. De modo que o interesse eterno dessa história para crianças está em que foi uma história construída pelas próprias crianças através de suas vovós, e pois exatamente como as crianças a queriam. E se vieram variantes é que os temperamentos variam e há que atendê-los 5 .

Como sabemos a história de Chapeuzinho Vermelho não foi originalmente criada para entreter crianças, como supunha Lobato. Surgiu em tempos ancestrais e se perpetuou nas tradições orais eurasiáticas, sendo encontradas variantes desse conto de Portugal a China. Mas, se a história da menina da capinha vermelha se tornou durante os séculos XIX e XX uma história paradigmática infantil, isso se deve ao fato de no final do século XVII, mais precisamente em 1695, Charles Perrault tê-la incluído na coletânea "Contos e Histórias do tempo passado", a qual foi escrita em meio a polêmica disputa dos Antigos contra os Modernos, da Academia Francesa de Letras. Provavelmente, Perrault se inspirou nos contos da tradição oral popular francesa, mas retirou ou atenuou elementos que considerava impróprios para os elegantes salões literários que frequentava. Outra narrativa desse mesmo conto que foi responsável por sua permanência e ajudou a fixar padrões que foram utilizados em inúmeras adaptações tanto literárias como cinematográficas, é o texto dos irmãos Grimm, de 1812, que segundo nos revela Robert Darnton, traz traços da produção de Perrault, visto que os irmãos Grimm recolheram seu conto de uma senhora alemã de ascendência francesa ${ }^{6}$.

Mas retornemos ao nosso assunto original: Lobato, sua construção literária e sua correspondência com os leitores infantis.

\footnotetext{
${ }^{5}$ Id., p. 252.

${ }^{6}$ Sobre essa temática ver: DEJEAN, Joan. Antigos contra Modernos. As guerras culturais e a construção de um fin de siècle. Rio de Janeiro: Civilização Brasileira, 2005. DARNTON, Robert. Histórias que os camponeses contam: o significado de Mamãe Ganso. In: o Grande massacre de gatos e outros episódios da história cultural francesa. 4 ed. Rio de Janeiro: Graal, 2001. ZIPES, Jack. The Irresistible Fairy Tale. The cultural and social History of a Genre. Princeton; Oxford: Princeton University Press, 2012. SILVA, Francisco Vaz da. Capuchinho Vermelho. Ontem e hoje. Lisboa, Círculo de Leitores, 2011.
} 
As mais de trezentas cartas que Lobato recebeu de crianças e jovens e que estão preservadas no arquivo do Instituto de Estudos Brasileiros, IEB/USP, foram enviadas a ele de 1931 a 1946, se referem a um período de tempo balizado por duas viagens importantes na vida do autor. Em março de 1931, ele retorna de sua estadia como adido comercial do governo brasileiro em Nova York, fixando sua residência em São Paulo e onde permanece até junho de 1946, quando ele e sua família mudamse para Buenos Aires e ali vivem por quase um ano.

Esses dois marcos temporais são bastante significativos na biografia de Lobato. Em Nova York ele passa pouco mais de quatro anos, de 1927 a 1931. Como adido comercial, ele procura alternativas possíveis para o crescimento brasileiro, seu trabalho dirige-se principalmente a processos para a exploração do ferro e do petróleo, que em sua opinião levariam o país ao desenvolvimento, este já alcançado pela nação norte-americana. Nesse contexto ele também entra em contato com a literatura infanto-juvenil que fazia sucesso na América do Norte, com as bibliotecas públicas que tinham seções especializadas para atender as crianças e começa a traduzir algumas dessas obras. No segundo momento temos um Lobato, já um autor infanto-juvenil consagrado, transferindo-se para Buenos Aires em junho de 1946. As dificuldades econômicas parecem ter sido o principal motor que levou o autor a se transferir para o país vizinho. Como suas obras completas haviam sido publicadas pela editora Americalee, ele contava com recursos na Argentina que não podiam ser transferidos para o Brasil. O país passava naquele momento por uma difícil crise de abastecimento de gêneros básicos, com pão, farinha de trigo e carne sendo racionados, o que fez Lobato proferir que ia para a Argentina para "comer bifes". A pilhéria que Lobato faz na verdade parece ser uma tentativa de encobrir sua desilusão com a situação social brasileira. Em carta ao escritor Jerônimo Monteiro ele afirma:

Ainda não pensei em voltar, porque as causas que me fizeram sair persistem e até acentuadas. O Brasil é um país com 8 milhões de quilômetros quadrados de miséria. Ora, isso é um pouco meio muito para um sujeito de maus pulmões que não é obrigado a viver aí. Miséria é uma coisa que tanto 
dói sendo na gente como nos outros - e a miséria brasileira estava a me doer demais ${ }^{7}$.

Poucos meses depois de escrever esta carta, em maio de 1947, Lobato volta ao Brasil. Problemas de saúde parecem ter sido o principal motivo para a volta.

Mas o que as cartas nos dizem? O que abordam? Em primeiro lugar devemos ressaltar que as cartas estão recheadas de afetividade, de intimidade, de carinho e admiração dos leitores para com seu escritor favorito. Isso se revela logo no início das cartas, pois as formas de tratamento são sempre: querido Lobato, querido amigo, amigo Lobato. As crianças se aproximam dele dessa forma e muitas explicam o tratamento empregado, pois já o conhecem profundamente por meio de suas obras. Nas missivas comentam sua vida cotidiana, as aulas, os professores, as provas, os estudos de piano, as leituras feitas, os empréstimos de livros, a dificuldade de encontrar determinado exemplar, a leitura feita com irmãos, pais e mães ou solitariamente. Mas, sem dúvida, o assunto que mais está presente em toda a epistolografia é a própria obra de Lobato. As crianças e os jovens comentam as últimas edições, tecem opiniões sobre determinados acontecimentos das narrativas e sugerem muitas coisas, como, por exemplo: obras a serem traduzidas, personagens a serem criados, assuntos a serem abordados, enfim, inúmeras solicitações que Lobato muitas vezes atende.

Nesse artigo abordaremos especificamente um conjunto de cartas muito especial: de uma menina chamada Maria de Lurdes, que assina as missivas como Rã ou Rãzinha, que não só se corresponde com Lobato, mas também se torna uma das personagens de sua obra, auxiliando Emília a fazer a Reforma da Natureza. De fato, ela aparece duas vezes na obra de Lobato, primeiramente na obra O Picapau Amarelo, publicada em 1939, ao liderar o grupo de crianças leitoras que gostariam de visitar o Sítio. Mas, como todos os personagens de Lobato estavam fora para o casamento de

${ }^{7}$ Carta de Lobato a Jerônimo Monteiro, 23/11/1946. Cartas Escolhidas. II tomo. São Paulo: Brasiliense, 1964. p. 201. 
Branca de Neve com o Príncipe Codadade, o grupo se contenta em passear no lombo de Quindim e conversar com o Burro Falante.

É em A Reforma da Natureza, de 1941, que a leitora aparece com muito destaque, participando de toda a obra. Logo no início da narrativa, D. Benta, Tia Anastácia, Pedrinho, Narizinho e Visconde são convidados pelo rei da Romênia para participar da Conferência de Paz. A narrativa ficcional de Lobato faz referência a segunda grande guerra e a turma do Sítio do Picapau Amarelo foi chamada a contribuir com a pacificação da Europa. Assim nas primeiras páginas do livro, Emília escreve à leitora convidando-a a reformar a natureza:

Assim que se pilhou sozinha, Emília correu a máquina de escrever e bateu uma carta para uma menina do Rio de Janeiro com a qual andava já a algum tempo se correspondendo e planejando coisas.

‘Querida Rã:

Estou só - só-só-ró-só-só! Todos foram para a Europa arrumar aqueles países mais amarrotados do que latas velhas e agora preciso que você venha passar uma temporada aqui. Você é das minhas: das que não concordam. Podemos realizar aquele plano de reforma da natureza. $[\ldots]^{8}$.

A leitora usando o pó de pirlimpimpim atende ao pedido de Emília e chegando ao Sítio se põe junto à boneca a reformar a Natureza. Percebemos pelas três cartas encontradas no acervo pesquisado, que muitas das transformações sugeridas pela Rã no decorrer do livro, de fato foram dadas a Lobato por meio da correspondência da leitora com o escritor. Provavelmente o número de cartas trocadas entre os dois foi maior do que o preservado, pois uma das cartas encontradas no acervo está incompleta e em nenhuma delas existe uma apresentação, isto é, o início da correspondência. Como Ângela de Castro Gomes (2004) nos revela, a escrita epistolográfica obedece uma série de regras, existem formas de apresentação, modelos pelos quais os correspondentes entram em contato de forma escrita, que nos permitem compreender o grau de afinidade e intimidade que se estabelece entre duas pessoas que trocam cartas.

${ }^{8}$ LOBATO, 1957, p. 202. 
Cartas são assim, um tipo de escrita que tem fórmulas muito conhecidas, porque aprendidas, inclusive nas escolas, como a datação, o tratamento, as despedidas e a assinatura, além de um papel mais apropriado, um timbre/ uma marca, um envelope, uma subscrição correta. [... $]^{9}$.

Ao analisar esse pequeno conjunto de cartas trocadas entre Maria de Lurdes e Monteiro Lobato percebemos que existem ausências e documentos que não foram preservados. Cotejando a correspondência com a obra publicada notamos que muitas sugestões feitas pela menina leitora deveriam ter sido dadas em cartas que não foram preservadas. Assim, não encontramos no dossiê pesquisado uma carta que inicia o relacionamento epistolográfico, com a apresentação de Maria de Lurdes e o início da correspondência, como ocorre em outros conjuntos de cartas no mesmo acervo. Em virtude dessa lacuna também não foi possível estabelecer dados importantes acerca da leitora, como, por exemplo, sua idade, se conhecia ou não pessoalmente o escritor, se era filha de algum amigo pessoal e não conseguimos sequer descobrir seu sobrenome. Sabemos somente que conhecia Lobato desde antes de 1939, pois aparece com outras crianças na obra O Picapau Amarelo, que vivia no Rio de Janeiro e que por meio das cartas colaborou com a escrita de A Reforma da Natureza. Algumas informações complementares são dadas pelo próprio Monteiro Lobato que assim apresenta a leitora: "A R̃̃ assim chamada por causa de sua magreza de menina de onze anos, era emilíssima, das que não concordam mesmo"10.

A carta escrita pela leitora em 10 de junho de 1940 parece ser a mais antiga conservada no acervo e se inicia com a menina comentando: "Ótima ideia essa da Emília modificando a Natureza! E não há nada mais cômodo do que pássaro-ninho". Esse início de carta nos revela que Lobato havia comentado com ela em correspondência anterior suas ideias para o novo livro que estava escrevendo, já que o pássaro-ninho é a primeira das reformas que Emília faz na Natureza. Nesta carta ela sugere uma "reforma" nos seres humanos, que na obra publicada é mencionada, mas que Emília

${ }_{9}^{9}$ GOMES, 2004. p. 20.

${ }^{10}$ LOBATO, 1957, p. 203. 
logo descarta, pois todos os seres humanos do Sítio haviam viajado, logo elas não poderiam modificá-los. Ainda nesse terceiro capítulo, intitulado O Passarinho-ninho aparece uma das sugestões dadas por Maria de Lurdes, pois, na carta sem data mas provavelmente de 1940, a menina sugere:

Emília, a sapeca da Emília, gostou das minhas modificações? Ótimo! Já arranjei outra: podemos modificar também o descarado do Rabicó. No focinho ele levará um certo aparelho de minha invenção, um pouco parecido com uma ratoeira que lhe dará um 'liscabão' daqueles, toda vez que ele for fossar minhocas ou roubar cocadas. As pernas serão trocadas por umas de tartaruga bem lesma, para impedi-lo de 'desaparecer veloz pela fímbria do horizonte' quando merecer um bom ponta-pé pedriniano11.

Lobato aproveita a ideia na obra, colocando-a como sugestão de Rãzinha em diálogo com Emília, mas não deixa de fazer uma brincadeira com a invenção tão inusitada. Assim Emília começa o diálogo:

[...] já pensei muito na reforma do Rabicó. Podemos transformá-lo em bípede e...

- E acabar com aquela mania de comer tudo quanto encontra, continuou Rã. Eu faria assim: no focinho punha uma espécie de ratoeira, sempre armada: quando ele avançasse num doce ou em qualquer coisa séria, como aquela coroa de casamento de narizinho, a ratoeira desarmava e segurava-lhe o focinho. E também dava pernas de tartaruga, para que não pudesse fugir quando Pedrinho o perseguisse com o bodoque.

Emília olhou Rã com ar desconfiado. Aquelas ideias pareciam-lhe absurdas. $[\ldots]$

Aquela menina estava com jeito de ser maluca... Apesar disso encarregou-a de reformar Rabicó. ${ }^{12}$

No capítulo seguinte A Reforma da Mocha, a menina e a boneca conversam sobre como "melhorar" a vaca Mocha. A célebre ideia de colocar torneirinhas nas tetas da vaca parte de Maria de Lurdes e é contestada por Emília:

Lá se foram as duas para o pastinho da Mocha, que estava pachorrentamente mascando umas palhas de milho. Ficaram diante dela. De mãos à cintura, discutindo a reforma.

- Eu mudava o depósito de leite - disse a Rãzinha. Punha torneirinha nas tetas para evitar o que hoje acontece: para tirar o leite os vaqueiros apertam as tetas com suas mãos sujíssimas - uma porcaria. Com o sistema de torneiras essas mãos não tocam nas tetas.

${ }_{11}$ Carta de Maria de Lurdes, sem data. Cx 1. Pasta 2. Doc 30. Dossiê Monteiro Lobato. Fundo Raul de Andrada e Silva. Arquivo Instituto de Estudos Brasileiros. IEB/USP.

12 LOBATO, 1957, p. 208. 
Emília deu uma risada gostosa.

- Que bobagem! Bem se vê que você é menina do Rio de Janeiro. Pois não sabe que a função das tetas é dar leite aos bezerros? Como pode um bezerrinho mamar em torneiras?

- Ensinávamos os bezerros a abrir as torneiras.

- Não - declarou Emília. Muito complicado. Na Mocha quero umas reformas úteis para ela mesma e não para as criaturas que a exploram. [...] $]^{13}$.

No final do capítulo as duas entram em um acordo e deixam metade das tetas com torneirinhas e a outra metade na forma original. Sobre essa modificação não temos o registro nas cartas preservadas no arquivo, mas imaginamos que a sugestão possa ter sido dada pela menina em uma carta que se extraviou.

Outra reforma que aparece na correspondência é a que Rã faz no Quindim. Assim ela aparece na mesma carta na qual está a sugestão feita para reformar Rabicó:

Ai! Tive uma idéia! Linda! Idéia mãe! Que tal se a Emília pintasse no casco do Quindim a Branca e Neve com todos os anãozinhos em volta e todos os bichinhos também, ao lado do Príncipe que a abraçava com um braço e com o outro esganava a bruxa? Aí o rinoceronte ficava tão lindo, tão lindo, tão tão tão lindo... [...] E se o Quindim tivesse em vez de chifre uma flecha do Cupido com um coração assado na ponta? Ah! A pobre vaca Mocha no mesmo instante propunha casamento. Ou! E se eles se casassem e surgisse um filho nas seguintes condições: na cabeça (que seria de boi) dois cifres do lado e um no meio tendo espetado uma cauda de vaca bem loura e espantamoscas; o couro em vez de ser córneo, seria feito de cabelos bovinos entrelaçados em forma de esteira; as pernas seriam compridas e peladas feito de bezerro com pés cascudos e duros; os olhos... de boi terno desmamado com sobrancelhas duras e bem saídas para não cair chuva; e a cauda do Quindim ${ }^{14}$.

Lobato aproveita a proposta no oitavo capítulo, adequando o que foi sugerido pela leitora em carta e modificando alguns argumentos:

No dia seguinte pularam da cama muito cedo e retomaram a obra de reforma da Natureza. Tudo era examinado e reformado no que lhes parecia torto. A Rãzinha continuava com as ideias mais absurdas, de verdadeira maluca. A reforma do Quindim que a Rã fez sozinha, era a coisa mais esquisita que se possa imaginar. Em vez do famoso chifre sobre o nariz, que é caraterístico de todos os rinocerontes, a Rã botou uma flecha de cupido com um coração assado na ponta. Assado, imaginem! E ornamentou os cascos de Quindim com pinturas: Branca de Neve com todos os anões. E trocou as quatros

${ }^{13}$ LOBATO, 1957, p. 214.

${ }^{14}$ Carta de Maria de Lurdes, sem data. Cx 1. Pasta 2. Doc 30. Dossiê Monteiro Lobato. Fundo Raul de Andrada e Silva. Arquivo Instituto de Estudos Brasileiros. IEB/USP. 
pernas do rinoceronte por quatro pernas diferentes - uma de veado, outra de ganso, outra de jacaré, outra de pau. E substituiu aquele couro duríssimo por um revestimento muito bem trançado de palhinha de cadeira. Cauda botou duas; depois três, depois dez, depois cem; deixou-o com um verdadeiro varal de caudas dando volta inteira em redor do pobre animal.

Lobato utiliza muitas das sugestões de Maria de Lurdes na construção de sua narrativa, no entanto as aproveita criando uma certa oposição ao que Emília pretendia fazer. Dessa forma, em vários trechos da obra temos Emília rebatendo as propostas da menina. Em certo trecho o autor a aproxima mesmo de uma grande personagem da literatura infantil pelo nonsense de suas sugestões: "Emília estava cada vez mais desconfiada da Rãzinha. Parecia a Alice no país das Maravilhas. Só vinha com disparates" 15 .

No início do décimo capítulo, as duas fazem as reformas nos livros transformando-os em livros comestíveis, o autor nos revela o motivo pelo qual Emília desconfiava das ideias estapafúrdias dadas por Rãzinha:

A maior parte das ideias da Rã eram desse tipo. Pareciam brincadeiras, e isso irritava Emília, que estava tomando muito a sério o seu programa de reforma do mundo. Emília sempre foi uma criaturinha muito séria e convencida. Não fazia nada de brincadeira.

- Parece incrível, Rã! - disse ela. Chamei você para me ajudar com ideias na reforma, mas até agora não saiu dessa cabecinha uma só coisa aproveitável só 'desmoralizações...'.

- Isso não! A ideia das tetas com torneiras na Mocha foi minha e você gostou muito. A da pulga também.

- Só essas. Todas as outras eu tive de jogar no lixo. Vamos ver mais uma coisa. Que acha que devemos fazer para a reforma dos livros? ${ }^{16}$

No entanto, mesmo discordando de muitas das sugestões da menina, as duas, Emília e Rã, dialogam e vão transformando os animais do Sítio, a casa, o mobiliário e os livros. Por toda a narrativa é essa escuta das ideias de uma e de outra e o exercício em chegar a um acordo sobre o que e como deve ou não ser reformado, que vai se construindo o enredo. As propostas da leitora têm sempre esse tom fantástico, nonsense, onde a liberdade criativa é a tônica. Emília, por mais incrível que pareça, é

${ }_{15}^{15}$ LOBATO, 1957, p. 210. 
a que pretende reformar a Natureza segundo um pensamento mais científico e racional, mas claro com resultados também totalmente inusitados.

Os leitores de A Reforma da Natureza não têm como saber que a menina que visita o Sítio do Picapau Amarelo é uma menina de carne e osso, uma das inúmeras leitoras que se correspondeu com Monteiro Lobato. Da mesma forma, não podem imaginar que muitas das ideias desenvolvidas no livro foram de fato dadas por ela ao escritor por meio de suas cartas. A documentação preservada, apesar de não estar completa, nos revela como Lobato estava atento e dialogava com seus leitores, estava aberto às suas sugestões. Criava e modificava suas obras em sintonia com o que as crianças e jovens gostariam de ler e pretendia com isso construir uma obra onde os leitores pudessem morar.

Se toda a obra literária é sempre uma construção na qual escritor e leitor se encontram em um mundo do texto, na qual o segundo cria a partir de sua própria realidade significado para aquilo que lê, refigurando o que o primeiro havia criado, poderíamos dizer que na obra de Lobato essa construção é efetivamente feita a quatro mãos. No caso específico da narrativa aqui analisada poderíamos dizer que temos a própria produção do texto feita de forma compartilhada. Quase como uma materialização do ato da leitura na acepção de Ricouer, temos a leitora escrevendo juntamente com o escritor a narrativa, que outros leitores refigurariam a partir de novas leituras ${ }^{17}$.

No entanto, essa construção tão peculiar e extraordinária, não deve ser supervalorizada a ponto de deixarmos de perceber que o autor tinha um projeto e veiculava suas ideias e concepções sobre o mundo quando escrevia as aventuras que se passavam no Sítio do Picapau Amarelo.

Lobato costumava afirmar que a criança era diferente do adulto, assim como a crisálida é da borboleta, concebia a infância de forma bastante peculiar: a criança é

17 RICOEUR, 1997; CERTEAU, 1996; CHARTIER, 1996. 
diferente, mas possui autonomia de pensamento, mesmo que esse pensamento nem sempre corresponda ao padrão adulto ${ }^{18}$. Outro ponto importante de ser analisado na visão de Lobato é a transitoriedade da infância: ela está destinada a não mais ser, a se tornar adulta. É nessa característica efêmera da criança que Lobato aposta suas fichas. Seu projeto era tornar a literatura palatável às crianças para que elas, gostando de ler, se tornassem ao crescer um público leitor. A constituição de um público leitor era, desde o século XIX, um sonho almejado por literatos e intelectuais, sem o qual não se via a constituição de uma nação. Dessa forma, durante os anos de formação do que viria a ser o público leitor, Lobato pretendia despertar a crítica, a autonomia de pensamento, a irreverência e também o humor nesse indivíduo em formação. Pretendia por meio da literatura transformar o mundo e, principalmente, o país no qual vivia, para isso convidava seus leitores a habitarem suas obras e construírem com ele um mundo feito de narrativas e novas realidades.

\section{referências}

AZEVEDO, Carmen Lucia de; CAMARGOS, Márcia R. de; SACCHETTA, Vladimir. Monteiro Lobato: furação na botocúndia. São Paulo: Senac, 1997.

CERTEAU, Michel de. A Invenção do Cotidiano. Artes de fazer. 2. ed. Petrópolis: Vozes, 1996.

CHARTIER, Roger. Práticas da leitura. Tradução: Cristiane Nascimento. São Paulo: Estação Liberdade, 1996.

DARNTON, Robert. O grande massacre de gatos. Rio de Janeiro: Graal, 1986.

DEJEAN, Joan. Antigos contra Modernos. As guerras culturais e a construção de um fin de siècle. Rio de Janeiro: Civilização Brasileira, 2005.

GOMES, Ângela de Castro. Escrita de si, escrita da História: a título de prólogo. In: Escrita de Si, Escrita da História. Rio de Janeiro: FGV, 2004.

LOBATO, Monteiro. A criança é a humanidade de amanhã. In: Conferências, Artigos e Crônicas. 5.ed. São Paulo: Brasiliense, 1968.

LOBATO, Monteiro. Obras Completas. São Paulo: Brasiliense, 1957. 30 vols.

LOBATO, Monteiro. A Reforma da Natureza. 7. ed. São Paulo: Brasiliense, 1957. p. 202.

RAFFAINI, Patricia Tavares. Pequenos Poemas em Prosa. Vestígios da leitura ficcional na infância brasileira, nas décadas de 30 e 40. 2008. Tese de doutorado em História Social, FFLCH/USP, São Paulo, 2008.

${ }_{18}$ LOBATO, 1968, p. 250. 
RICOEUR, Paul. Tempo e Narrativa. Vol. III. São Paulo: Papirus, 1997.

SILVA, Francisco Vaz da. Capuchinho Vermelho. Ontem e hoje. Lisboa: Círculo de Leitores, 2011.

SOARES, Gabriela Pellegrino. A Semear horizontes: leitura literárias na formação da infância, Argentina e Brasil (1915-1954). Belo Horizonte: UFMG, 2007.

ZIPES, Jack. The Irresistible Fairy Tale. The cultural and social History of a Genre. Princeton; Oxford: Princeton University Press, 2012.

recebido em: 01.10.2017

aceito em: 22.11.2017 